\title{
Particulate-Matter Related Respiratory Diseases
}

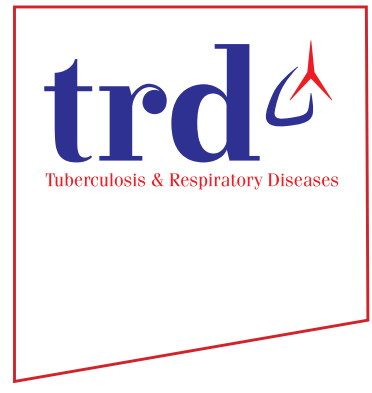

\author{
Sun Young Kyung, M.D., Ph.D. ${ }^{1,2}$ and Sung Hwan Jeong, M.D., Ph.D. ${ }^{1,2}$ \\ ${ }^{1}$ Department of Allergy, Pulmonary and Critical Care Medicine, Gachon University Gil Medical Center, Incheon, ${ }^{2}$ Gachon \\ Particulate Matter Associated Disease Institute, Gachon University, Incheon, Korea
}

Particulate matter (PM) is suspended dust that has a diameter of $<10 \mu \mathrm{m}$ and can be inhaled by humans and deposited in the lungs, particularly the alveoli. Recent studies have shown that PM has an adverse effect on respiratory diseases. The aim of this article is to review respiratory diseases associated with PM. According to existing studies, PM is associated with chronic obstructive pulmonary disease, bronchial asthma, and several other respiratory diseases and increases the mortality rates of these diseases. Moreover, increased exposure in the high concentration of atmospheric PM is associated with the development of lung cancer. The most simple and common way to protect an individual from airborne PM is to wear a face mask that filters out PM. In areas of high concentration PM, it is recommended to wear a face mask to minimize the exposure to PM. However, the use of N95 or KF94 masks can interfere with respiration in patients with chronic respiratory diseases who exhibit low pulmonary function, leading to an increased risk of respiratory failure. Conclusionally, reduction of the total amount of PM is considered to be important factor and strengthening the national warning notification system to vulnerable patients and proper early management of exacerbated patients will be needed in the future.

Keywords: Face Mask; Particulate Matter; Respiratory Diseases

\section{Introduction}

Particulate matter (PM) is suspended dust that has a diameter of $<10 \mu \mathrm{m}\left(\mathrm{PM}_{10}\right)$ and can be inhaled by humans and deposited in the lungs, particularly the alveoli. In addition to $\mathrm{PM}_{10}$, $\mathrm{PM}$ with diameter $<2.5 \mu \mathrm{m}\left(\mathrm{PM}_{2.5}\right)$ and $<0.1\left(\mathrm{PM}_{0.1}\right)$ is classified as fine and ultrafine PM, respectively ${ }^{1,2}$. A major

Address for correspondence: Sung Hwan Jeong, M.D., Ph.D. Department of Allergy, Pulmonary and Critical Care Medicine, Gachon University Gil Medical Center, 21 Namdong-daero 774beon-gil, Namdong-gu, Incheon 21565, Korea

Phone: 82-32-458-2872, Fax: 82-32-458-2891

E-mail: jsw@gilhospital.com

Received: Apr. 10, 2019

Revised: Oct. 10, 2019

Accepted: Jan. 21, 2020

Published online: Mar. 10, 2020

(c) It is identical to the Creative Commons Attribution Non-Commercial License (http://creativecommons.org/licenses/by-nc/4.0/). The Korean Academy of Tuberculosis and Respiratory Diseases. source of PM is the combustion of fossil fuels from human activity; however, natural sources, such as yellow dust, are also significant. Domestic PM consists of fine dust from China, seasonal yellow dust, and domestic-generated air pollutants ${ }^{3,4}$. As PM poses considerable health risks, individual countries have set maximum acceptable concentrations of PM within the atmosphere, based on the results of concentration prediction systems to estimate levels of $\mathrm{PM}^{1,5-7}$.

In 2005, as outlined by the World Health Organization (WHO), the maximum acceptable annual average concentration of $\mathrm{PM}_{10}$ was $\leq 20 \mu \mathrm{g} / \mathrm{m}^{3}$, with a limit of $\leq 50 \mu \mathrm{g} / \mathrm{m}^{3}$ per 24 -hour period. In Korea, the annual and daily average concentrations of $\mathrm{PM}_{10}$ are $<50$ and $<100 \mu \mathrm{g} / \mathrm{m}^{3}$, respectively. The annual and daily average concentrations of $\mathrm{PM}_{2.5}$ are $<15$ and $35 \mu \mathrm{g} / \mathrm{m}^{3}$, respectively. Overall concentrations of $\mathrm{PM}_{10}$ and $\mathrm{PM}_{2.5}$ are above $81 \mu \mathrm{g} / \mathrm{m}^{3}$ and $36 \mu \mathrm{g} / \mathrm{m}^{3}$, respectively, and therefore the PM concentration forecast grade is designated as 'bad' in Korea (Tables 1, 2) 1.8 .

According to current literature, exposure to PM leads to increased pulmonary inflammation and respiratory symptoms aggravation due to oxidative stress and direct toxic injury ${ }^{5,6}$. This is particularly dangerous for patients with pre-existing respiratory diseases, as exposure to PM can lead to acute ex- 
Table 1. Overview of guidelines for particulate matter (PM)

\begin{tabular}{|lcccccc|}
\hline & \multicolumn{2}{c}{$\mathbf{P M}_{10}\left(\mu \mathrm{g} / \mathrm{m}^{3}\right)$} & & \multicolumn{2}{c|}{$\mathbf{P M}_{2.5}\left(\mu \mathrm{g} / \mathbf{m}^{3}\right)$} \\
\cline { 2 - 3 } \cline { 5 - 6 } & $\begin{array}{c}\text { Daily } \\
\text { average }\end{array}$ & $\begin{array}{c}\text { Annual } \\
\text { average }\end{array}$ & & $\begin{array}{c}\text { Daily } \\
\text { average }\end{array}$ & $\begin{array}{c}\text { Annual } \\
\text { average }\end{array}$ \\
\hline RHO & 50 & 20 & & 25 & 10 \\
Republic of Korea & 100 & 50 & & 35 & 15 \\
\hline
\end{tabular}

$\mathrm{PM}_{10}$ : $\mathrm{PM}$ with diameter $<10 \mu \mathrm{m} ; \mathrm{PM}_{2.5}$ : $\mathrm{PM}$ with diameter $<2.5 \mu \mathrm{m}$; WHO: World Health Organization.

Table 2. Particulate matter (PM) concentration forecast grade in Korea

\begin{tabular}{|lcccc|}
\hline & \multicolumn{4}{c|}{ PM concentration $\left(\mu \mathrm{g} / \mathrm{m}^{3}\right)$} \\
\cline { 2 - 5 } & Good & Moderate & Bad & Very bad \\
\hline $\mathrm{PM}_{10}$ & $0-30$ & $31-80$ & $81-150$ & $\geq 151$ \\
$\mathrm{PM}_{2.5}$ & $0-15$ & $16-50$ & $51-100$ & $\geq 101$ \\
\hline
\end{tabular}

$\mathrm{PM}_{10}$ : $\mathrm{PM}$ with diameter $<10 \mu \mathrm{m} ; \mathrm{PM}_{2.5}: \mathrm{PM}$ with diameter $<2.5 \mu \mathrm{m}$.

acerbation of their ailment. It has also been reported that longterm exposure to high concentrations of PM increases the prevalence of chronic obstructive pulmonary disease (COPD) and lung cancer in adults, leading to a decline in pulmonary function $^{9-12}$. The high concentration of PM in the atmosphere has a profound effect on the prevalence of chronic respiratory diseases, and the risk of acute exacerbation (which can prove fatal) ${ }^{13,14}$. Additionally, $\mathrm{PM}_{2.5}$ exposure is associated with a long recovery time, more leading to an increase in both the mortality rate and the overall medical burden. Therefore, it is of the utmost importance that effective policies and medical practices are put into place to minimize the public health risks associated with PM exposure (Table 3$)^{15}$.

\section{PM and Pulmonary Function}

Pulmonary function is an indicator of respiratory health. Generally, pulmonary function increases from birth until the mid-20s, after which it begins to decrease. Air pollution, especially PM exposure, is associated with decreased pulmonary function, leading to an increase in the rate of lung function decline in adults ${ }^{16-19}$.

Large-scale cohort studies of the effect of fine dust on pulmonary function in adults are typically based on National Health and Nutrition Examination Surveys (NHANEs). Notably, the Swiss Study on Air Pollution and Lung Diseases in Adults (SAPALDIA), and the German study on the Influence of Air Pollution on Lung Function, Inflammation, and Aging (SALIA), show interesting results. In the SAPALDIA study, 9,651 adults, aged 18-60 years, were monitored over a period of 11 years. The average forced vital capacity (FVC) and mean forced expiratory volume in 1 second $\left(\mathrm{FEV}_{1}\right)$ decreased by
Table 3. Influence of PM on the respiratory system

\begin{tabular}{|l|}
\hline \multicolumn{1}{|c|}{ Influence of PM on the respiratory system } \\
\hline Increases mortality \\
Increases the incidence of malignant tumors \\
Increases the incidence of chronic respiratory disease \\
exacerbations such as COPD and asthma \\
Increase or worsen overall respiratory symptoms \\
Reduce lung function growth in children \\
Causes temporary loss of lung function in normal people \\
Increases airway inflammation and increases airway \\
hyperresponsiveness \\
Reduces pulmonary diffusing capacity in lung function \\
\hline
\end{tabular}

PM: particulate matter; COPD: chronic pulmonary disease.

$3.4 \%$ and $1.6 \%$, respectively. The $\mathrm{PM}_{10}$ concentration declined during the observation period, which was associated with reduced lung function decline ${ }^{18}$. In the SALIA study, $\mathrm{FEV}_{1}$ and FVC decreased by $4.7 \%$ and $3.4 \%$, respectively, and the $\mathrm{FEV}_{1} /$ FVC decreased by $1.1 \%$, with an increase in $\mathrm{PM}_{10}$ concentration by $10 \mu \mathrm{g} / \mathrm{m}^{3}$ between 1985 and 1994. Thus, lung function was negatively affected, but the decline in pulmonary function was attenuated by reducing PM exposure through environmental improvement ${ }^{13}$. However, it is not yet fully understood how other factors affect pulmonary function, such as age, other pollutants, individual susceptibility, and genetic factors.

\section{Effect of PM on COPD and Bronchial Asthma}

COPD has been widely studied in relation to fine dust exposure in pulmonary disease ${ }^{1,8,20}$. Studies showed that the rate of hospitalization of patients suffering from COPD increased with increasing exposure to $\mathrm{PM}^{20-22}$. A meta-analysis carried out in Korea showed that COPD admissions increased by $\sim 2.7 \%$ (95\% confidence interval $[\mathrm{CI}], 1.9 \%-3.6 \%$ ) with an increase in $\mathrm{PM}_{10}$ concentration of $10 \mu \mathrm{g} / \mathrm{m}^{3}$ (odds ratio [OR], 1.027 ; $95 \%$ CI, 1.019-1.036). In addition, a positive correlation between an increase in $\mathrm{PM}_{10}$ concentration and COPD mortality was also found: COPD mortality increased by $1.1 \%$ (95\% CI, 0.8\%-1.4\%) with an increase in $\mathrm{PM}_{10}$ concentration of $10 \mu \mathrm{g} / \mathrm{m}^{3}$ (OR, 1.011; 95\% CI, 1.008-1.014) $)^{8}$. These results strongly suggest that exposure to PM increased both the hospital admission and mortality rate of COPD. Recent studies have shown that hospitalization due to deterioration of COPD is associated more with atmospheric concentrations of $\mathrm{PM}_{2.5}$ versus $\mathrm{PM}_{10}$. This is especially significant for the 14-90-day period prior to hospital admission (relative risk, 1.06-1.32) ${ }^{14,15}$. About 1.6 million deaths from COPD are believed to be due to air pollution ${ }^{23}$. In Korea, there has been no detailed study on the effect of air pollution and PM on the aggravation of COPD 
patients; thus, further research is imperative to better understand the effect of PM exposure on COPD patients.

In addition to COPD, asthma has also been studied in relation to fine dust exposure ${ }^{4,24}$. Exposure to PM can cause allergic sensitization and asthma exacerbation ${ }^{24,25}$. In asthmatic patients, both the exhaled nitric oxide fraction (FeNO) and airway hyperresponsiveness increases due to aggravation of the allergic inflammatory response. Moreover, asthmatic patients also show reduced lung volume or lung diffusion capacity ${ }^{24}$. Subsequently, PM exposure has been reported to lead to an increase in hospital visits as symptoms including decreased lung function, coughing, wheezing, and dyspnea worsen. In particular, $\mathrm{PM}_{2.5}$ significantly increased the incidence and prevalence of asthma. According to recent reports, for every $10 \mu \mathrm{g} / \mathrm{m}^{3}$ increase in $\mathrm{PM}_{2.5}$ concentration, the total number of hospital, out-patient, and emergency room visits increased by $0.67,0.65$, and $0.49 \%$, respectively. These findings indicate a significant correlation between PM exposure and acute asthmatic exacerbations ${ }^{26}$. In addition, both domestic and international studies have shown that long-term exposure to PM increases the overall prevalence of asthma ${ }^{12}$.

\section{PM and Interstitial Lung Disease}

In 2014, an international study of the relationship between air pollution and idiopathic pulmonary fibrosis (IPF) reported that concentrations of ozone and nitrogen dioxide in airborne fine dust were associated with acute exacerbation of IPF at 6 weeks after initial exposure ${ }^{27}$. A recent study reported that the FVC of IPF patients was reduced by $46 \mathrm{~mL}$ with an increase in $\mathrm{PM}_{10}$ exposure concentration of $5 \mu \mathrm{g} / \mathrm{m}^{3}$, indicating that the increase of PM was closely associated with the progression of $\mathrm{IPF}^{28}$. In the 2018 French cohort study, Cohorte Fibrose (COFI), it was reported that as the concentration of $\mathrm{PM}_{10}$ and $\mathrm{PM}_{2.5}$ increased by $10 \mu \mathrm{g} / \mathrm{m}^{3}$, the IPF mortality rate increased significantly, by 2.01- and 7.93-fold, respectively ${ }^{29}$. These results suggest that an increase in PM exposure significantly decreases pulmonary function, leading to an increase in mortality, as well as acute exacerbation, of IPF $^{30}$.

\section{PM and Lung Cancer}

In 2013, the WHO and the International Agency for Research on Cancer (IARC) announced that PM is carcinogenic $^{31}$, and that increased atmospheric PM concentrations are associated with lung cancer development ${ }^{32,33}$. In the European Study of Cohorts of Air Pollution Effects (ESCAPE), the hazard ratio of lung cancer was 1.22 and 1.18 for an increase in $\mathrm{PM}_{10}$ concentration of $10 \mu \mathrm{g} / \mathrm{m}^{3}$, and in $\mathrm{PM}_{2.5}$ of $5 \mu \mathrm{g} / \mathrm{m}^{3}$, respectively $^{34,35}$. In a comprehensive meta-analysis conducted in Korea in 2015, the risk of lung cancer increased by 1.09-fold
(95\% CI, 1.01-1.14) when the concentration of $\mathrm{PM}_{25}$ increased by $10 \mu \mathrm{g} / \mathrm{m}^{3}$. A correlation between $\mathrm{PM}_{10}$ concentration and lung cancer incidence was also observed; however, the correlation was comparatively weak compared to that between lung cancer risk and $\mathrm{PM}_{2.5}$ concentration (1.08-fold increased risk; 95\% CI, 1.00-1.17) ${ }^{8}$. In addition, lung cancer incidence was higher in smokers who were exposed to high amounts of $\mathrm{PM}_{2.5}$; it was confirmed that fine PM affects smokers' lung cancer development to a significantly greater degree relative to healthy people $e^{6,31,32}$. It is estimated that about 500,000 lung cancer deaths can be attributed to air pollution ${ }^{23}$. Both $\mathrm{PM}_{10}$ and $\mathrm{PM}_{2.5}$ were reported to significantly increase the mortality rate in lung cancer patients in 2017 and 2018 meta-analyses ${ }^{36}$. Thus, to reduce lung cancer prevalence and mortality, control of PM generation and avoidance of PM exposure, together with smoking cessation, are of the utmost importance ${ }^{33}$.

\section{PM and Pneumonia Mortality Rate}

PM increases airway inflammation in the lungs, leading to increased levels of both inflammatory cytokines and neutrophils, and an increase in serum 8-isoprostane in bronchoalveolar lavage fluid or induced sputum ${ }^{25,37}$. These findings accord with the incidence of pneumonia, and it is known that the risk and mortality rate of pneumonia increase in both children and adults with higher PM exposure ${ }^{34,38,39}$. A recent meta-analysis showed that the incidence rate of pneumonia in children increased by $1.5 \%$ and $1.8 \%$ for every $10 \mu \mathrm{g} / \mathrm{m}^{3}$ increase in $\mathrm{PM}_{10}$ and $\mathrm{PM}_{2.5}$, respectively, demonstrating the relationship between PM and pneumonia ${ }^{11}$. In another meta-analysis, the overall mortality rate (relative risk, 1.02) of respiratory disease patients was significantly increased for every $10 \mu \mathrm{g} / \mathrm{m}^{3}$ increase of $\mathrm{PM}_{2.5}$ in fine dust ${ }^{10}$.

\section{PM and Protective Face Masks}

The most simple and common way to protect against airborne fine dust is to wear a mask that filters out fine dust or gas. Protective masks against PM used in Korea include the N95, KF94, and KF99 models. Such precautionary measures are vital, as natural air pollution phenomena, such as yellow sand, pose severe health risks in Korea. To specifically combat the danger posed by yellow sand, a specialized mask (KF80) has been developed ${ }^{40}$. Among filtering face respirators, the N95 and KF94 masks are the most commonly used, protecting the respiratory tract from fine dust exposure in industrial workers. These masks are also used to protect against respiratory pathogens in hospitals and public places ${ }^{41}$. Both the N95 and KF94 masks are superior to the KF80 mask in preventing PM inhalation. However, industrial workers who wear these masks for long periods tend to have subjective complaints, 
including discomfort when breathing. It is known that, in addition to carbon dioxide accumulation, a decrease in the concentration of inhaled oxygen can lead to an increase in respiratory dead space ${ }^{42}$. Although the N95 and KF94 masks have no significant effect on pulmonary function in healthy people or patients with mild respiratory issues, for patients with low pulmonary function and high levels of respiratory distress, caution should be taken when using these masks. All filtration masks (KF80, KF94, and N95) are commercially available and can prevent harmful exposure to PM due to the inflow of fine dust into the body. It is recommended that both the general public and people suffering from mild and moderate chronic respiratory diseases and/or cardiovascular diseases use these preventative measures ${ }^{40,41}$. However, the use of N95 and KF94 masks by people with COPD (stage C/D), or advanced IPF is associated with severe respiratory failure; thus, caution is necessary regarding their use. Further research on the effectiveness of masks for preventing PM exposure is needed for patients with advanced respiratory diseases ${ }^{8}$.

\section{Conclusion}

Several studies have shown that exposure to high concentrations of PM leads to an increase in hospitalization and mortality rates in patients suffering from COPD. Acute exacerbation of bronchial asthma and IPF is also linked to high concentrations of PM. Long-term exposure to PM is associated with lung cancer development; particularly, high concentrations of $\mathrm{PM}_{2.5}$ have been linked with acute exacerbation and increased prevalence of chronic respiratory disease in smokers aged 60 years and over. Therefore, patients with chronic respiratory diseases are vulnerable to high concentrations of environmental PM and should limit outdoor activities and use medication regularly to reduce the risk of acute exacerbation. Visiting a medical institution for immediate treatment is recommended if any acute exacerbation symptoms are experienced. In addition, in high PM concentration environments, it is recommended that a face mask be worn to minimize exposure. However, for patients with chronic pulmonary diseases and very low pulmonary function, caution must be taken when using the N95 and KF94 masks. Numerous health problems are associated with PM exposure, all of which can lead to the progression and worsening of lung disease; thus, it is extremely important that national policy helps manage resources of PM and focuses on preventative medical care. Strengthening the notification system to vulnerable patients and proper management of PM production control are considered to be important factors in suppressing prevalence in chronic respiratory disease, decreasing the hospitalization rate, and reducing the mortality associated with acute exacerbations.

\section{Authors' Contributions}

Conceptualization: Jeong SH. Methodology: Kyung SY. Formal analysis: Jeong SH, Kyung SY. Writing - original draft preparation: Jeong SH, Kyung SY. Writing - review and editing: Jeong SH. Approval of final manuscript: all authors.

\section{Conflicts of Interest}

No potential conflict of interest relevant to this article was reported.

\section{Funding}

No funding to declare.

\section{References}

1. World Health Organization. WHO Air quality guidelines for particulate matter, ozone, nitrogen dioxide and sulfur dioxide [Internet]. Geneva: World Health Organization; 2005 [cited 2019 Dec 10]. Available from: http://whqlibdoc.who.int/ hq/2006/WHO_SDE_PHE_OEH_06.02_eng.pdf.

2. World Health Organization. Ambient air pollution: a global assessment of exposure and burden of disease [Internet]. Geveva: World Health Organization; 2016 [cited 2019 Dec 10]. Available from: http://apps.who.int/iris/bitstream/ 10665/250141/1/9789241511353-eng.pdf?ua=1.

3. Ministry of Environment. What is the particulate matter? [Internet]. Sejong: Ministry of Environment; 2018 [cited 2019 Dec 10]. Available from: http://www.me.go.kr/ebook/svs/gt/ view/159.

4. Yang HJ, Kim SH, Jang AS, Kim SH, Song WJ, Kim TB, et al. Guideline for the prevention and management of particulate matter/yellow dust-induced adverse health effects on the patients with bronchial asthma. J Korean Med Assoc 2015;58:1034-43.

5. Dockery DW, Pope CA 3rd, Xu X, Spengler JD, Ware JH, Fay ME, et al. An association between air pollution and mortality in six U.S. cities. N Engl J Med 1993;329:1753-9.

6. Pope CA 3rd, Burnett RT, Thun MJ, Calle EE, Krewski D, Ito $\mathrm{K}$, et al. Lung cancer, cardiopulmonary mortality, and long-term exposure to fine particulate air pollution. JAMA 2002;287:1132-41.

7. WHO Regional Office for Europe Review of evidence on health aspects of air pollution - revihaap project: technical report. Copenhagen: WHO Regional Office for Europe; 2013.

8. Kyung SY, Kim YS, Kim WJ, Park MS, Song JW, Yum H, et al. Guideline for the prevention and management of particulate matter/Asian dust particle-induced adverse health effect on 
the patients with pulmonary diseases. J Korean Med Assoc 2015;58:1060-9.

9. Zhang S, Li G, Tian L, Guo Q, Pan X. Short-term exposure to air pollution and morbidity of COPD and asthma in East Asian area: a systematic review and meta-analysis. Environ Res 2016;148:15-23.

10. Fajersztajn L, Saldiva P, Pereira LA, Leite VF, Buehler AM. Short-term effects of fine particulate matter pollution on daily health events in Latin America: a systematic review and meta-analysis. Int J Public Health 2017;62:729-38.

11. Nhung NT, Amini H, Schindler C, Kutlar Joss M, Dien TM, Probst-Hensch N, et al. Short-term association between ambient air pollution and pneumonia in children: a systematic review and meta-analysis of time-series and case-crossover studies. Environ Pollut 2017;230:1000-8.

12. Abbey DE, Burchette RJ, Knutsen SF, McDonnell WF, Lebowitz MD, Enright PL. Long-term particulate and other air pollutants and lung function in nonsmokers. Am J Respir Crit Care Med 1998;158:289-98.

13. Schikowski T, Adam M, Marcon A, Cai Y, Vierkotter A, Carsin AE, et al. Association of ambient air pollution with the prevalence and incidence of COPD. Eur Respir J 2014;44:614-26.

14. Zielinski M, Gasior M, Jastrzebski D, Desperak A, Ziora D. Influence of particulate matter air pollution on exacerbation of chronic obstructive pulmonary disease depending on aerodynamic diameter and the time of exposure in the selected population with coexistent cardiovascular diseases. Adv Respir Med 2018;86:227-33.

15. Atkinson RW, Kang S, Anderson HR, Mills IC, Walton HA. Epidemiological time series studies of PM2.5 and daily mortality and hospital admissions: a systematic review and metaanalysis. Thorax 2014;69:660-5.

16. Gauderman WJ, McConnell R, Gilliland F, London S, Thomas D, Avol E, et al. Association between air pollution and lung function growth in southern California children. Am J Respir Crit Care Med 2000;162(4 Pt 1):1383-90.

17. Gehring U, Gruzieva O, Agius RM, Beelen R, Custovic A, Cyrys J, et al. Air pollution exposure and lung function in children: the ESCAPE project. Environ Health Perspect 2013;121:135764.

18. Downs SH, Schindler C, Liu LJ, Keidel D, Bayer-Oglesby $\mathrm{L}$, Brutsche MH, et al. Reduced exposure to PM10 and attenuated age-related decline in lung function. N Engl J Med 2007;357:2338-47.

19. Pope CA 3rd, Ezzati M, Dockery DW. Fine-particulate air pollution and life expectancy in the United States. N Engl J Med 2009;360:376-86.

20. Gan WQ, FitzGerald JM, Carlsten C, Sadatsafavi M, Brauer M. Associations of ambient air pollution with chronic obstructive pulmonary disease hospitalization and mortality. Am J Respir Crit Care Med 2013;187:721-7.

21. Li J, Sun S, Tang R, Qiu H, Huang Q, Mason TG, et al. Major air pollutants and risk of COPD exacerbations: a systematic review and meta-analysis. Int J Chron Obstruct Pulmon Dis 2016;11:3079-91.

22. Sunyer J, Basagana X. Particles, and not gases, are associated with the risk of death in patients with chronic obstructive pulmonary disease. Int J Epidemiol 2001;30:1138-40.

23. Schraufnagel DE, Balmes JR, Cowl CT, De Matteis S, Jung $\mathrm{SH}$, Mortimer K, et al. Air pollution and noncommunicable diseases: a review by the Forum of International Respiratory Societies' Environmental Committee, part 2: air pollution and organ systems. Chest 2019;155:417-26.

24. Guarnieri M, Balmes JR. Outdoor air pollution and asthma. Lancet 2014;383:1581-92.

25. Thurston GD, Kipen H, Annesi-Maesano I, Balmes J, Brook RD, Cromar K, et al. A joint ERS/ATS policy statement: what constitutes an adverse health effect of air pollution? An analytical framework. Eur Respir J 2017;49:1600419.

26. Tian Y, Xiang X, Juan J, Sun K, Song J, Cao Y, et al. Fine particulate air pollution and hospital visits for asthma in Beijing, China. Environ Pollut 2017;230:227-33.

27. Johannson KA, Vittinghoff E, Lee K, Balmes JR, Ji W, Kaplan GG, et al. Acute exacerbation of idiopathic pulmonary fibrosis associated with air pollution exposure. Eur Respir J 2014;43:1124-31.

28. Winterbottom CJ, Shah RJ, Patterson KC, Kreider ME, Panettieri RA Jr, Rivera-Lebron B, et al. Exposure to ambient particulate matter is associated with accelerated functional decline in idiopathic pulmonary fibrosis. Chest 2018;153:1221-8.

29. Sese L, Nunes H, Cottin V, Sanyal S, Didier M, Carton Z, et al. Role of atmospheric pollution on the natural history of idiopathic pulmonary fibrosis. Thorax 2018;73:145-50.

30. Carey IM, Atkinson RW, Kent AJ, van Staa T, Cook DG, Anderson HR. Mortality associations with long-term exposure to outdoor air pollution in a national English cohort. Am J Respir Crit Care Med 2013;187:1226-33.

31. Straif K, Cohen A, Samet J. Air pollution and cancer [Internet]. Lyon: International Agency for Research on Cancer; 2013 [cited 2019 Dec 10]. Available from: http://www.iarc.fr/en/ publications/books/sp161/AirPollutionandCancer161.pdf.

32. Hamra GB, Guha N, Cohen A, Laden F, Raaschou-Nielsen O, Samet JM, et al. Outdoor particulate matter exposure and lung cancer: a systematic review and meta-analysis. Environ Health Perspect 2014;122:906-11.

33. Huang F, Pan B, Wu J, Chen E, Chen L. Relationship between exposure to PM2.5 and lung cancer incidence and mortality: a meta-analysis. Oncotarget 2017;8:43322-31.

34. MacIntyre EA, Gehring U, Molter A, Fuertes E, Klumper $\mathrm{C}$, Kramer U, et al. Air pollution and respiratory infections during early childhood: an analysis of 10 European birth cohorts within the ESCAPE Project. Environ Health Perspect 2014;122:107-13.

35. Raaschou-Nielsen O, Andersen ZJ, Beelen R, Samoli E, Stafoggia M, Weinmayr G, et al. Air pollution and lung cancer incidence in 17 European cohorts: prospective analyses from 
the European Study of Cohorts for Air Pollution Effects (ESCAPE). Lancet Oncol 2013;14:813-22.

36. Kim HB, Shim JY, Park B, Lee YJ. Long-term exposure to air pollutants and cancer mortality: a meta-analysis of cohort studies. Int J Environ Res Public Health 2018;15:E2608.

37. Suhaimi NF, Jalaludin J. Biomarker as a research tool in linking exposure to air particles and respiratory health. Biomed Res Int 2015;2015:962853.

38. Cai Y, Schikowski T, Adam M, Buschka A, Carsin AE, Jacquemin B, et al. Cross-sectional associations between air pollution and chronic bronchitis: an ESCAPE meta-analysis across five cohorts. Thorax 2014;69:1005-14.

39. Kyung SY, Jeong SH. Adverse health effects of particulate mat- ter. J Korean Med Assoc 2017;60:391-8.

40. Langrish JP, Li X, Wang S, Lee MM, Barnes GD, Miller MR, et al. Reducing personal exposure to particulate air pollution improves cardiovascular health in patients with coronary heart disease. Environ Health Perspect 2012;120:367-72.

41. Langrish JP, Mills NL, Chan JK, Leseman DL, Aitken RJ, Fokkens PH, et al. Beneficial cardiovascular effects of reducing exposure to particulate air pollution with a simple facemask. Part Fibre Toxicol 2009;6:8.

42. Roberge RJ, Coca A, Williams WJ, Powell JB, Palmiero AJ. Physiological impact of the N95 filtering facepiece respirator on healthcare workers. Respir Care 2010;55:569-77. 